\title{
Chemical composition, antibacterial and antifungal activity of the essential oil of Pinus patula growing in Rwanda
}

\author{
Tomani Jean Claude ${ }^{1, *}$, Murangwa Christine ${ }^{2}$, Bajyana Songa ${ }^{2}$, Mukazayire Marie Jeanne ${ }^{1}$, \\ Ingabire Mukazi Goretti ${ }^{1}$, Chalchat Jean Claude ${ }^{3}$ \\ ${ }^{1}$ Research Program in Phytomedecine and Life Science, Institute of Scientific and Technological Research, Huye, Rwanda \\ ${ }^{2}$ Department of Biotechnology, Faculty of Science, National University of Rwanda, Huye, Rwanda \\ ${ }^{3}$ Laboratory of Photochemistry Molecular and Macromolecular, Chemistry of Essential Oils, Blaise Pascal Clermont University, Aubière \\ Cédex, France
}

Email address:

tomanfils@yahoo.fr (Tomani J. C.)

To cite this article:

Tomani Jean Claude, Murangwa Christine, Bajyana Songa, Mukazayire Marie Jeanne, Ingabire Mukazi Goretti, Chalchat Jean Claude. Chemical Composition, Antibacterial and Antifungal Activity of the Essential oil of Pinus Patula Growing in Rwanda. American Journal of Biomedical and Life Sciences. Vol. 2, No. 3, 2014, pp. 55-59. doi: 10.11648/j.ajbls.20140203.11

\begin{abstract}
Essential oils and their components are increasingly spreading as naturally occurring antimicrobial agents. In this work the chemical composition and the antimicrobial properties of Pinus patula essential oils, a wild Pinaceae, which grows in several regions of Rwanda, were characterized and assessed. The essential oil was obtained by steam distillation and the chemical composition was determined using GC/MS. The in vitro antimicrobial activity of the essential oil was studied against two Gram-negative bacteria (Streptococcus pyogenis, Pseudomonas solanacearum) and one Gram-positive bacteria (Staphylococcus aureus) and two fungi (Pycularia oryzae, Colletotrichum coffeanum) using a broth macrodilution method and by agar diffusion method. During the chemical composition analysis, seventy-four components making up $99.11 \%$ of the oil were detected while only fifty components making up $95.70 \%$ of the oil were characterized, $\beta-$ phellandrene (18.98\%), $\alpha$-pinene (15.91\%), bornyl acetate (7.89\%), $\beta$-caryophyllene $(7.41 \%)$, limonene $(5.67 \%)$ being the major constituents. The results of the in vitro antimicrobial assay showed that essential oil extracted from the rwandese Pinus patula has a strong activity against all tested bacteria and fungi, exception done to Colletotrichum coffeanum fungi.
\end{abstract}

Keywords: Essential Oil, Pinus Patula, Rwanda, Chemical Composition, Antimicrobial Activity

\section{Introduction}

Incidence of microbial infections has increased in recent decades and numerous pathogenic microorganisms are subject to detailed researches in the therapeutical and pharmaceutical field. The majority of diseases seen in the population of developing countries should be ranged by order of importance. Diarrhea diseases are heading the list, followed by acute respiratory infections and then come skin diseases, etc [1]. Different microorganisms, being bacteria or fungi, are responsible of most of these infections and are linked to the low level of hygienic conditions, common for developing countries. They are at the origin of a significant human toll as well as the cause of public fear, economic loss, and other adverse outcomes [2]. Staphylococcus aureus, a gram positive bacterium, is reported to be the most pathogen species of the Staphylococcus genus. It is reported to be responsible of numerous animal and human infections including post operative wound infections, food poisoning, osteomyelitis, just to mention few [3, 4]. Streptococcus pyogenis, a gram negative bacterium of the A group of Lance Field, is the source of red sore throats, skin infections (impetigo), abscess, broncho-pulmonary infections.

Leaving aside human parasitic microbes, one can note that plant pathogens are raising serious concerns worldwide including starvation conditions due to a huge loss of crops. The crop loss due to fungal infections and their emerging resistance to numerous used pesticides are raising serious concerns to food self-reliance, particularly in developing countries. Pseudomonas solanacearum, a 
gram negative bacterium, is reported to be responsible of bacterial wilt of numerous crop plants worldwide [5] and thus leading to the loss or decrease of harvest. Colletotricum coffeanum is a phytopathogen fungus that causes anthracnose to the coffee. The seed deterioration increases when humidity and temperature conditions are favorable to the microorganism's development [6-8]. Pyricularia oryzae is responsible of one of the most important diseases of rice, pyriculariose, that every year causes the loss of 10 to $30 \%$ of the harvesting yield [9].

To fight against the above mentioned threats, some studies were reported in the literature and have led to the discovery of potential antimicrobial drugs. However, there is an increasing spread of multidrug-resistant strains associated to the abundant use of antimicrobial agents. To control the increasing resistance of pathogenic microbes, the discovery of new antimicrobials and compounds with novel modes of action and fewer side effects must be developed. An increasing interest, both in the industry and in the pharmaceutical firms, is paid to new compounds from natural sources where essential oils and plant extracts have play an important role in the discovery of new therapeutic alternatives $[3,10]$.

In the literature, the essential oil of Pinus patula has been reported to show antifungal activity against 6 fusarium species (Fusarium avenaceum, F. culmorum, F. oxysporum, F. subglutinans, $F$. verticillioides, F. nygamai) and against other three fungi, Alternaria alterna, Microdochium nivale and Bottrytis cinerea [11]. To the best of our knowledge, Amri and coworkers' study is the only one that reported the bioactivity of the essential oil of Pinus patula. The present study is aimed at investigating the antimicrobial effect of essential oil of Pinus patula against three bacteria strains (Streptococcus pyogenis, Pseudomonas solanacearum, Staphylococcus aureus) and two fungi strains (Pycularia oryzae, Colletotrichum coffeanum) and hence contributing to the discovery of new potential products for respiratory diseases and biopesticides. In fact, essential oils-based biopesticides may contribute to the air, water and/or soil pollution decreasing since they are biodegradable and are thus strong candidates to replace organic resisting pollutants such as DDT and other synthetic pyrethrinoids still used for food stuffs in Rwanda.

\section{Material and Methods}

\subsection{Plant Material and Essential Oils Extraction}

The used plant material for the essential oils distillation are fresh needles of Pinus patula harvested from the arboretum of the National University of Rwanda, located in Huye district, in the Southern province of Rwanda. The plant material was collected in September. The plant material was identified by the botanist and the voucher specimen was deposited in the National herbarium of
Rwanda in the Institute of Scientific and Technological Research (IRST). The essential oil was obtained by steam distillation of the fresh needles during $8 \mathrm{~h}$. Then, the essential oil was collected and dried over anhydrous Magnesium sulfate and refrigerated, in a sealed vial, at $4^{\circ} \mathrm{C}$ before analysis. The yield based on dried weight of the sample was calculated (w/w).

\subsection{Chemical Composition Analysis}

GC analyses were performed on a Hewlett Packard HP6890 equipped with a split / splitless injector $\left(280^{\circ} \mathrm{C}\right)$, a split ration 1:10, using a HP-5 capillary column (25 m x $0.25 \mathrm{~mm}$, film thickness $0.25 \mu \mathrm{m})$. The temperature program was $50^{\circ} \mathrm{C}(5 \mathrm{~min})$ rising to $300^{\circ} \mathrm{C}$ at a rate of $5^{\circ} \mathrm{C} / \mathrm{min}$. Helium was used as the carrier gas at a flow rate of $1.1 \mathrm{ml} / \mathrm{min}$. The injection of each sample consisted of $1.0 \mu \mathrm{l}$ of oil diluted to $10 \% \mathrm{v} / \mathrm{v}$ with acetone. GC/MS analyses were performed on a Hewlett Packard 5973/6890 system operating in EI mode $(70 \mathrm{eV})$, equipped with a split/splitless injector $\left(280^{\circ} \mathrm{C}\right)$, a split ration $1: 10$, using two different columns: a fused silica HP-5MS capillary column $(25 \mathrm{~m} \times 0.25 \mathrm{~mm}$, film thickness $0.25 \mu \mathrm{m})$, and a HP-Innowax capillary column $(60 \mathrm{~m} \times 0.25 \mathrm{~mm}$, film thickness $0.25 \mu \mathrm{m})$. The temperature program for the HP-5 MS column was $50^{\circ} \mathrm{C}(\mathrm{min})$ rising to $300^{\circ} \mathrm{C}$ at rate of $5^{\circ} \mathrm{C} / \mathrm{min}$ and for the HP-Innowax column, $50^{\circ} \mathrm{C}-250^{\circ} \mathrm{C}$ at a rate of $5^{\circ} \mathrm{C} / \mathrm{min}$. Helium was used as the carrier gas at a flow rate of $1.1 \mathrm{ml} / \mathrm{min}$. Retention indices for all compounds were determined according to the Van den Dool approach [12]. The identification of components was based on comparison of their mass spectra with those of Wiley [13], Adams [14] and Joulain [15] libraries, as well as by comparison of their retention indices with literature data. The compositional data of nine geographical origins were submitted.

\subsubsection{Microbial Strains and Midia}

The in vitro antimicrobial activity of the essential oil was studied against two Gram-negative bacteria (Streptococcus pyogenis, Pseudomonas solanacearum) and one Grampositive bacterium (Staphylococcus aureus) and two fungi (Pycularia oryzae, Colletotrichum coffeanum). The used bacterial strains have been isolated at the Laboratory of Foodstuffs, Medicines, Water and Toxics (LADAMET, National University of Rwanda) while fungi strains were provided by the laboratory of the Agricultural Faculty of the National University of Rwanda. Standard MuellerHinton agar and broth were used as the bacterial culture media while Sabouraud dextrose agar and broth were used as fungal culture media.

\subsection{Antimicrobial Assays}

\subsubsection{Agar Well Diffusion Assay}

A culture was diluted with a sterile physiological saline solution with reference to the McFarland standard to 
achieve an inoculum of approximately $106 \mathrm{CFU} \mathrm{ml}^{-1}[16]$. A $5 \mathrm{ml}$ portion of this inoculum was placed onto the surface of pre-dried agar plates, according to the strain to be inoculated, and allowed to remain in contact for $1 \mathrm{~min}$. Excess of inoculums was removed using a sterile syringe and the plates were allowed to dry for $20 \mathrm{~min}$ at room temperature. As described by Das [17], holes of $8 \mathrm{~mm}$ were aseptically punched in the culture medium and different concentrations of essential oils were introduced into the bored agar well. Sterile Physiological solution was used as a negative control. After $1 \mathrm{~h}$ of rest at room temperature to allow the essential oils to diffuse across the surface, all treated and untreated plates were incubated at $37^{\circ} \mathrm{C}$ for 24 $\mathrm{h}$. The inhibition zone was measured in millimeter and the assay was carried out in triplicate. The essential oil was evaluated as extremely active $(+++)$, very active $(++)$, active (+) and non active (-) depending on the size of the inhibition zone diameter surrounding the essential oil holes.

According to Elaissi and coworkers [18], depending on the inhibition zone diameter, results are evaluated to be: not sensitive (-) when the inhibition zone diameter is $<8 \mathrm{~mm}$, sensitive $(+)$ for the $8 \mathrm{~mm} \leq$ diameter $\geq 14 \mathrm{~mm}$, very sensitive $(++) 14 \mathrm{~mm}<$ diameter $\geq 28 \mathrm{~mm}$ and extremely sensitive $(+++)$ for inhibition zone diameter $>28 \mathrm{~mm}$. If there is no clear zone around holes, this means that the essential oil doesn't develop activity against the tested germ.

\subsubsection{The determination of the Minimum Inhibitory Concentration (MIC)}

For the determination of the minimum inhibitory concentration for each strain, the agar dilution method was developed according to Mann and coworker [19]. The essential oil was diluted with a physiological solution with Tween 80 and then to the culture medium to give concentrations ranging from 0 to $1.5 \%(\mathrm{v} / \mathrm{v})$. Plates, prepared in triplicate, were spot inoculated with $3 \mu \mathrm{l}$ aliquots of culture in Nutrient Broth or Brain-Heart Infusion Broth. After inoculation, using a sterilized platinum handle, plates were incubated at $37^{\circ} \mathrm{C}$ for $24 \mathrm{~h}$ for bacteria and at room temperature for 3 days for fungi. The medium culture, according to the test strain, with only a $0 \cdot 5 \%(\mathrm{v} / \mathrm{v})$ physiological solution was used as a negative control. The minimum inhibitory concentration (MIC) was determined as the lowest concentration of essential oil to result in no growth of the inoculums on two of the three plates. The presence of one or two colonies was disregarded.

\section{Results and Discussions}

\subsection{Essential Oil Extraction}

The steam distillation of fresh Pinus patula needles gave yellowish essential oil (yield: $0.13 \%$, w/w). This yield is not constant since fluctuations occur with season [20]. As mentioned above, used plant materials were collected in September, at the end of the summer season. This would justify the low yield in essential oil, compare to the $0.4 \%$ reported in the literature [11], since in this season, a great amount of the produced essential oils is used in process of limiting the excessive plant transpiration.

Table 1. Results of the antimicrobial test

\begin{tabular}{lll}
\hline Test strains & Essential oil & Control \\
\hline Staphyloccocus aureus & +++ & - \\
Streptoccocus pyogenes & ++ & - \\
Pseudomonas solanacearum & +++ & - \\
Pyricularia oryzae & +++ & - \\
Colletotricum coffeanum & - & - \\
\hline
\end{tabular}

Table 2. Minimum Inhibitory Concentration (MIC)

\begin{tabular}{ll}
\hline Test strains & MIC $(\mathbf{m l} / \mathbf{m l})$ \\
\hline Staphylococcus aureus & 0.5 \\
Streptococcus pyogenes & 1.2 \\
Pseudomonas solanacearum & 0.5 \\
Pyricularia oryzae & 1.5 \\
Colletotrichum coffeanum & No activity \\
\hline
\end{tabular}

Table 3. Essential oil chemical composition

\begin{tabular}{|c|c|}
\hline Components & Content (\%) \\
\hline Tricyclene & 0.76 \\
\hline$\alpha$-pinene & 15.91 \\
\hline Camphene & 3.41 \\
\hline Sabinene & 0.29 \\
\hline$\beta$-pinene & 2.4 \\
\hline Myrcene & 2.13 \\
\hline$\alpha$-phellandrene & 0.19 \\
\hline$\delta$-3-carene & 4.07 \\
\hline p-Cymene & 0.98 \\
\hline Limonene & 5.67 \\
\hline$\beta$-phellandrene & 18.98 \\
\hline E- $\beta$-ocimene & 0.47 \\
\hline$\gamma$-terpinene & 0.10 \\
\hline Terpinolene & 1.41 \\
\hline Para cymenene & 0.22 \\
\hline Menth-2-en-1-ol cis & 0.07 \\
\hline Menth-2-en-1-ol trans & 0.13 \\
\hline Trans pinocarveol & 0.34 \\
\hline Camphor & 0.09 \\
\hline Camphene hydrate & 0.27 \\
\hline Borneol & 0.48 \\
\hline Terpinene-4-ol & 0.68 \\
\hline Cryptone & 2.43 \\
\hline$\alpha$ - terpineol & 0.77 \\
\hline Thymol methyl ether & 0.10 \\
\hline Cuminaldehyde & 0.29 \\
\hline Phelandral & 0.43 \\
\hline Bornyle acetate & 7.89 \\
\hline p-Cymene-7-ol & 0.17 \\
\hline Piperitenone & 0.15 \\
\hline Myrtenol acetate & 0.18 \\
\hline Menth-1-en-7-al & 0.15 \\
\hline$\alpha$ - terpenyle acetate & 0.48 \\
\hline$\alpha$-ylangene & 0.18 \\
\hline
\end{tabular}




\begin{tabular}{ll}
\hline Components & Content (\%) \\
\hline$\alpha$ - copaene & 0.15 \\
$\beta$-bourbonene & 0.16 \\
$\beta$-cubebene & 0.24 \\
$\beta$-elemene & 0.15 \\
Longifolene & 0.21 \\
$\beta$-caryophyllene & 7.41 \\
$\beta$-copaene & 0.14 \\
Muurola-3,5-diene cis & 0.06 \\
$\alpha$ - humulene & 1.66 \\
$\gamma$-muuroene & 0.38 \\
Germacrene-D & 3.75 \\
$\gamma$-amorphene & 0.42 \\
Bicyclogermacrene & 0.24 \\
$\alpha$ - muurolene & 0.61 \\
$\gamma$-cadinene & 0.41 \\
$\delta$-cadinene & 1.09 \\
$\alpha$ - cadinene & 0.13 \\
Spathulenol & 0.52 \\
Caryophylene oxide & 1.99 \\
Salvial-4(14)-en-1-one & 0.08 \\
Humulene-2-epoxide & 0.25 \\
Epi cubenol & 0.22 \\
Epi $\alpha$ - cadinol & 0.43 \\
Epi $\alpha$ - muurolol & 0.77 \\
$\alpha$ - muurolol & 0.26 \\
$\alpha$ - cadinol & 1.49 \\
Benzyle benzoate & 0.27 \\
Total identified compounds & 95.7 \\
Monoterpen fraction & 57.2 \\
Oxygenated monoterpens & 15.1 \\
Sesquiterpens fraction & 17.4 \\
Oxygenated sesquiterpens & 6.3 \\
\hline & \\
\hline & \\
\hline
\end{tabular}

\subsection{Chemical Analysis}

The results of the GC-MS analyses are presented in Table 3, where the compounds are listed in order of their elution time on the columns. During the chemical composition analysis, a total of seventy- four components making up $99.1 \%$ of the oil were detected while only fifty components making up $95.7 \%$ of the oil were characterized. The monoterpens fraction is the most represented with $57.2 \%$ of the total identified components, followed by Sesquiterpens (17.4\%), oxygenated monoterpens (15.1\%) and lastly comes the oxygenated sesquiterpens $(6.3 \%)$. The major components were $\beta$-phellandrene (19\%), $\alpha$-pinene $(15.9 \%)$, bornyle acetate $(8.0 \%), \beta$-caryophyllene $(7.4 \%)$, and limonene $(5.7 \%)$. Tunisian and Japanese Pinus patula essential oils were reported to contain $\alpha$-pinene and $\beta$ phellandrene as their major components where $\alpha$-pinene was almost twice the amount of $\beta$-phellandrene [11]. In our essential oil, results are reversed and, though in same range, the amount of $\beta$-phellandrene dominates that of $\alpha$-pinene.

\subsection{Antimicrobial Activity}

The table 1 and 2 contain results obtained by agar diffusion and broth dilution methods respectively. For the agar diffusion method, the essential oil activity is shown by the formation of the blank zone around holes containing essential oil. The importance of the strain sensibility on essential oil depends on the diameter of the inhibition zone. Among the tested strains, two bacteria strains, Staphyolococcus aureus and Pseudomonas solanacearum, gram positive and gram negative bacteria respectively, were the most sensible followed by another bacterium Streptococcus pyogenes. Among the fungi strains, only Pyricularia oryzae was sensible while Colletotrichum coffeanum was resistant to various concentrations. The present study has demonstrated that the essential oil of Pinus patula is a potential source of natural antimicrobials. Many natural compounds, including plant phenols and terpenoids, have been widely used because of their strong antimicrobial properties against food-borne pathogens, and therefore they can be applied as novel preservatives in the food industry [21]. Pinus patula essential oil is effective against both Gram-positive and Gram-negative bacteria. The activity of the oils would be expected to relate to the respective composition of the plant volatile oils, the structural configuration of the constituent components of the volatile oils and their functional groups and possible synergistic interactions between components [22]. The presence of an oxygen function in the framework increases the antimicrobial properties of terpenoids [23]. Also, an alkenyl substituent (1-methylethenyl) results in increased antibacterial activity, as seen in limonene [1-methyl-4-(1methylethenyl)-cyclohexene], compared to an alkyl (1methylethyl) substituent as in $p$-cymene [1-methyl-4-(1methylethyl)-benzene] [22]. In addition, the susceptible organisms were principally Gram-negative, which suggests alkylation influences Gram reaction sensitivity of the bacteria. The importance of the antimicrobial activity of alkylated phenols in relation to phenol has been reported [24]. Their data suggest that an allylic side chain seems to enhance the inhibitory effects of a component and chiefly against Gram-negative organisms.

Biological activity of essential oils depends on either its major compounds or on synergic effect between its different components. As previously mentioned, the chemical composition analysis of essential oil of the Rwandese Pinus patula provided seventy-four detected compounds, $\alpha$-pinene and $\beta$-phellandrene being its major components. Through literature, $\alpha$-pinene has been reported fungicidal and insecticidal [25] and antibacterial $[25,26]$. Though the amount of $\beta$-phellandrene dominated that of $\alpha$-pinene, we think that $\alpha$-pinene contributes to the shown antimicrobial activity during our study.

\section{Conclusion}

Chemical characterization and antimicrobial screening studies on plant-based essential oils could lead to a discovery of new natural antimicrobials. The present study confirmed the antimicrobial properties of Pinus patula essential oil on almost all tested strains. The GC-MS 
analysis for its chemical composition resulted in a new chemotype of Pinus patula and has a high content of monoterpens with inversion, in terms of content, of their major components. Yet, it has to be evaluated if the major compounds are responsible of the shown activity or if it is due to the synergic effect among other minor compounds. The results of this study confirmed the possibility of using Pinus patula essential oils in controlling plant diseases or animal skin and respiratory infections.

\section{Acknowledgement}

The authors wish to thank the Institute of Scientific and Technological Research for financial support, the Laboratory of Foodstuffs, Medicines, Water and Toxics (LADAMET/National University of Rwanda) for their technical assistance and the Agriculture Faculty/National University of Rwanda for strains provision.

\section{References}

[1] WHO. Epidemiology and Management of Common Skin Diseases in Children in Developing Countries. WHO, Geneva, Switzeland 2005.

[2] Morens DM, Fauci AS. Emerging Infectious Diseases: Threats to Human Health and Global Stability. PLoS Pathog 2013; 9:e1003467.

[3] Ghalem BR, Benali M. Antibacterial activity of leaf essential oils of Eucalyptus globulus and Eucalyptus camaldulensis. African Journal of Pharmacy and Pharmacology 2008;2:211-5.

[4] Jeffrey J. Peterson M. Postoperative Infection Radiol Clin N Am 2006;44:439-50.

[5] Huang Y, Sequeira L. Identification of a Locus That Regulates Multiple Functions in Pseudomonas solanacearum. Journal of Bacteriology 1990:4728-31.

[6] Bothast RJ. Fungal deterioration and related phenomena in cereals, legumes and oilseeds. Food and Nutrition Press 1978:210-43

[7] Christensen CM. Influence of moisture content temperature and time of storage up on invasion of rough rice by storage fungi. Phytopathology 1969;59:145-8.

[8] Harrison JG, Perry DA. Studies on the mechanisms of barley seed deterioration. Ann Appl Biol 1976;84: 57-62.

[9] Skamnioti P, Gurr SJ. Against the grain: safeguarding rice from rice blast disease. Trends in Biotechnology 2009;27:141-50.

[10] Singh G, Maurya S. Antimicrobial, Antifungal and insecticidal investigations on essential oils ò an overview. Natural Product Radiance 2005;4:179-92.

[11] Amri I, Lamia H, Gargouri S, Hanan M, Mahfoudhi M, Fezzani $\mathrm{T}$, et al. Chemical composition and Biological activities of essential oils of Pinus patula. Natural Product
Communications 2011;6:1-6.

[12] Van Den Dool H, Kratz PD. A generalization of the retention index system including linear temperature programmed gas-liquid partition chromatography. J Chromatography 1963; 11:463-71.

[13] McLafferty FW, Stauffer DB. The Wiley NBS registry of Mass Spectral Data. JWiley and Son 1989;2nd Edition edn.

[14] Adams R. Identification of Essential Oil Components by Gas Chromatography/Quadrupole Mass Spectroscopy. Allured Publishing Corp IL Carol Stream edn 2001

[15] Joulain D, Kônig WA. The Atlas of Spectral Data of Sesquiterpene Hydrocarbons. EBVerlag edn (EBVerlag, ed) 1998.

[16] Burt SA, Reinders RD. Antibacterial activity of selected plant essential oils against Escherichia coli O157:H7. Letters in Applied Microbiology 2003;36:162-7.

[17] Das K, Tiwari RKS, Shrivastava DK. Techniques for evaluation of medicinal plant products as antimicrobial agent: Current methods and future trends. Journal of Medicinal Plants Research 2010;4:104-11.

[18] Elaissi A, Rouis Z, Mabrouk S, Bel Haj Salah K, Aouni M, Khouja ML, et al. Correlation Between Chemical Composition and Antibacterial Activity of Essential Oils from Fifteen Eucalyptus Species Growing in the Korbous and Jbel Abderrahman Arboreta (North East Tunisia). Molecules 2012;17:3044-57.

[19] Mann CM, Markham JL. A new method for determining the minimum inhibitory concentration of essential oils. Journal of Applied Microbiology 1998; 84:538-44.

[20] Ntezurubanza L. Les huiles essentielles du Rwanda. LASEVE, Québec, Canada 2000:248p.

[21] Friedman M, Henika PR, Mandrell RE. Bactericidal activities of plant essential oils and some of their isolated constituents against Campylobacter jejuni, Escherichia coli, Listeria monocytogenes and Salmonella enterica. J Food Prot 2002;65:1545-60.

[22] Dorman HJD, Deans SG. Antimicrobial agents from plants: antibacterial activity of plant volatile oils. Journal of Applied Microbiology 2000;88:308-16.

[23] Naigre R, Kalck P, Roques C, Roux I, Michel G. Comparison of antimicrobial properties of monoterpenes and their carbonylated products. Planta Medica $1996 ; 62: 275-7$

[24] Pelczar MJ, Chan ECS, Krieg NR. Control of microorganisms, the control of microorganisms by physical agents. Microbiology 1988:469-509.

[25] Rivas da Silva AC, Monteiro Lopes P, Barros de Azevedo MM, Machado Costa DC, Alviano CS, Alviano DS. Biological Activities of $\alpha$-Pinene and $\beta$-Pinene Enantiomers. Molecules 2012;17: 6305-16.

[26] Leite AM, Lima EdO, Souza ELd, de M, Diniz FFM, Trajano VN, et al. Inhibitory effect of $\beta$-pinene, $\alpha$-pinene and eugenol on the growth of potential infectious endocarditis causing Gram-positive bacteria. Brazilian Journal of Pharmaceutical Sciences 2007; 43. 